\title{
Post-surgery anxiety and depression in prostate cancer patients: prevalence, longitudinal progression, and their correlations with survival profiles during a 3-year follow-up
}

\author{
Su $\mathrm{Hu}^{1} \cdot \mathrm{Li} \mathrm{Li}^{1} \cdot$ Xiaoling $\mathrm{Wu}^{1} \cdot$ Zhengqing $\mathrm{Liu}^{1} \cdot \mathrm{Adan}^{\mathrm{Fu}}{ }^{1}$ \\ Received: 21 August 2020 / Accepted: 17 October 2020 / Published online: 7 January 2021 \\ (C) The Author(s) 2021
}

\begin{abstract}
Background Anxiety and depression are more frequent in cancer patients than general population and may be correlated with cancer prognosis; however, their value in prostate cancer patients is largely unknown. We aimed to evaluate prevalence of anxiety and depression in prostate cancer survivors post the surgeries, and their correlations with patients' disease-free survival (DFS) and overall survival (OS).

Methods A hundred and ninety-four patients with prostate cancer who underwent radical prostatectomy were enrolled. After discharged from hospital, patients were assessed for post-surgery anxiety and depression every 3 months using Zung Self-rating Anxiety/Depression Scale (SAS/SDS) for a total of 36 months. In addition, disease conditions, DFS, and OS were also documented.

Results SAS score $(P<0.001)$, anxiety rate $(P=0.004)$, SDS score $(P<0.001)$, and depression rate $(P<0.001)$ gradually elevated from baseline to month 36 in prostate cancer patients. Anxiety at baseline $(P=0.009)$ and anxiety at 3 years $(P=$ $0.017)$ were correlated with worse DFS, and anxiety at baseline $(P=0.009)$ was also correlated with shorter OS in prostate cancer patients. Furthermore, depression at baseline $(P=0.005)$ and depression at 2 years $(P=0.008)$ were associated with unfavorable DFS, and depression at baseline $(P=0.001), 1$ year $(P=0.025)$, and 2 years $(P=0.008)$ were associated with worse OS in prostate cancer patients. Moreover, multivariate Cox's proportional hazards regression analysis elucidated that depression at baseline $(P=0.027)$ was an independent predictive factor for shorter DFS in prostate cancer patients.

Conclusion Anxiety and depression both gradually deteriorate, and they correlate with unfavorable survival profile in prostate cancer patients after radical prostatectomy.
\end{abstract}

Keywords Anxiety $\cdot$ Depression $\cdot$ Disease-free survival $\cdot$ Overall survival $\cdot$ Prostate cancer

\section{Introduction}

Anxiety and depression have long been the most common mental disorders that impact on approximately $6-7 \%$ of the worldwide population, and they often coexist in the same individual $[1,2]$. These mental disorders not only sabotage psychiatric health but also result in physical dysfunction, such as increasing cardiovascular disease risk and cause fatigue in

$\mathrm{Su} \mathrm{Hu}$ and Li Li contributed equally to this work.

Adan Fu

annepu3906488@163.com

1 Department of Intensive Care Unit, The Central Hospital of Wuhan, Tongji Medical College, Huazhong University of Science and Technology, 26 Shengli Street, Wuhan 430014, China affected individuals $[3,4]$. In the past decades, anxiety and depression are more and more noted in cancer patients as they tend to have obviously increased prevalence in cancer patients than in the general populations $[5,6]$. The mechanism underlying the occurrence of anxiety and depression in cancer patients is complex. Nowadays, several possible mechanisms including the change of biopsychosocial status, some antitumor drugs, and neuron affected tumors have been implied [7-9]. However, although anxiety and depression present with a relatively high prevalence in cancer patients, very limited patients can obtain proper intervention, what's worse is that these two mental disorders are increasingly reported to be correlated with worse prognosis $[10,11]$.

Among males, prostate cancer is currently the most frequent cancer in over a half of countries worldwide [12]. Prostate cancer treatments are categorized by the disease 
condition; for localized patients, the first line methods are prostatectomy and radio-therapy, and for metastatic patients, hormone therapy and chemotherapy are the most frequently applied methods in practice [13, 14]. Most of the patients with prostate cancer present with a favorable survival profile; therefore, the number of prostate cancer survivors after the surgeries is very considerable; although survived from the disease, patients have to confront various issues that often impairs their health status and quality of life, such as the fear of relapse and decrease of physical function [15, 16]. Recently, there have been reports of the development of anxiety and depression in prostate cancer survivors, which is not surprising in view of the incidence of these two mental disorders in other cancers [17], while the impact of anxiety and/or depression on prostate cancer patients' clinical outcome remains ambiguous, and corresponding studies are very few.

Therefore, we investigated the prevalence of anxiety and depression in prostate cancer survivors post the surgeries, and their correlations with patients' disease-free survival (DFS) as well as overall survival (OS) in this current study.
Table 1 Clinical characteristics of patients

\begin{tabular}{|c|c|}
\hline Items & Prostate cancer patients $(N=194)$ \\
\hline \multicolumn{2}{|l|}{ Demographics } \\
\hline Age (years), $\mathrm{M} \pm \mathrm{D}$ & $62.5 \pm 9.0$ \\
\hline Education duration (years), median (IQR) & $9.0(6.0-12.0)$ \\
\hline \multicolumn{2}{|l|}{ Marry status, no. (\%) } \\
\hline Married & $129(66.5)$ \\
\hline Single/divorced/widowed & $65(33.5)$ \\
\hline \multicolumn{2}{|l|}{ Employment status before surgery, no. (\%) } \\
\hline Employed & $66(34.0)$ \\
\hline Unemployed & $128(66.0)$ \\
\hline Smoker, no. (\%) & $84(43.3)$ \\
\hline \multicolumn{2}{|l|}{ Comorbidities } \\
\hline Hypertension, no. $(\%)$ & $83(42.8)$ \\
\hline Hyperlipidemia, no. (\%) & $45(23.2)$ \\
\hline Diabetes, no. $(\%)$ & $35(18.0)$ \\
\hline CKD, no. $(\%)$ & $32(16.5)$ \\
\hline \multicolumn{2}{|l|}{ Disease features } \\
\hline \multicolumn{2}{|l|}{ PSA level, no. (\%) } \\
\hline$\leq 10 \mathrm{ng} / \mathrm{ml}$ & $46(23.7)$ \\
\hline $10-20 \mathrm{ng} / \mathrm{ml}$ & $100(51.5)$ \\
\hline$\geq 10-20 \mathrm{ng} / \mathrm{ml}$ & $48(24.8)$ \\
\hline \multicolumn{2}{|l|}{ Gleason score, no. $(\%)$} \\
\hline$\leq 6$ & $44(22.7)$ \\
\hline 7 & $107(55.2)$ \\
\hline$\geq 8$ & $43(22.1)$ \\
\hline \multicolumn{2}{|l|}{ Pathological T stage, no. (\%) } \\
\hline pT2 & $112(57.7)$ \\
\hline pT3 & $76(39.2)$ \\
\hline pT4 & $6(3.1)$ \\
\hline \multicolumn{2}{|l|}{ Pathological N stage, no. (\%) } \\
\hline $\mathrm{pN} 0$ & $140(72.2)$ \\
\hline $\mathrm{pN} 1$ & $54(27.8)$ \\
\hline \multicolumn{2}{|l|}{ Surgical margin status, no. (\%) } \\
\hline Negative & $160(82.5)$ \\
\hline Positive & $34(17.5)$ \\
\hline
\end{tabular}

$M \pm S D$, mean \pm standard deviation; $I Q R$, interquartile range; $C K D$, chronic kidney disease; $P S A$, prostate-specific antigen 
a

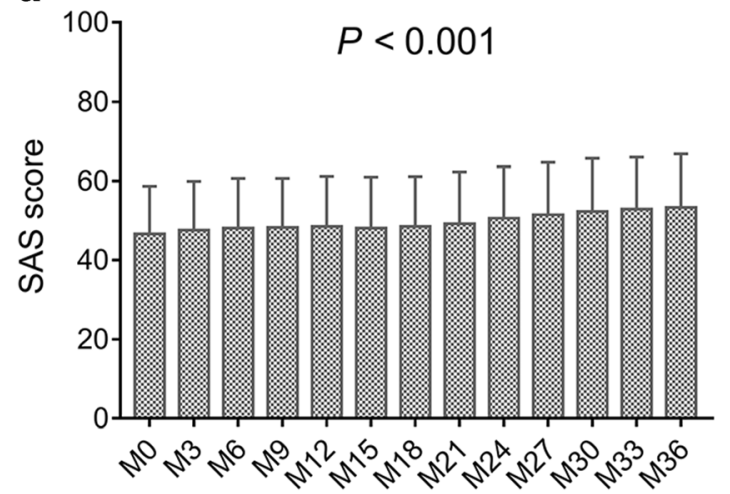

b

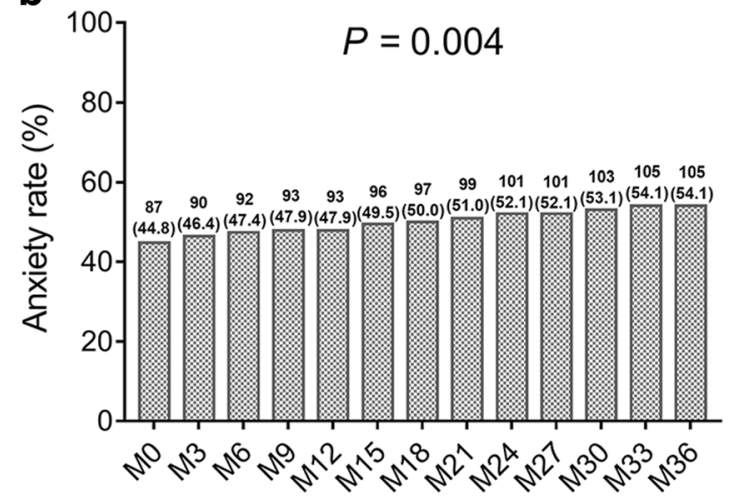

Fig. 1 SAS score and anxiety rate at each follow-up. The SAS score at each follow-up (a), and anxiety rate at each follow-up (b) in prostate cancer patients after surgery. SAS, Zung Self-rating Anxiety scale

\section{Methods}

\section{Patients}

From January 2015 to December 2016, 194 patients with prostate cancer who underwent radical prostatectomy in our hospital were consecutively enrolled in this study. The eligible criteria for enrollment were as follows: (1) confirmed diagnosis of primary prostate cancer based on histopathological verification of adenocarcinoma in prostate biopsy cores; (2) age $\geq 18$ years; (3) underwent radical prostatectomy; (4) able to understand the study consents and complete the anxiety and depression assessments; (5) willing to comply with follow-up schedule. Patients with following conditions were not included in the study: (1) known other serious mental disorders (excepting anxiety and depression); (2) severe cognitive impairment; (3) history of severe neurological diseases or neurodegenerative disease; (4) complicated with other cancers. All patients signed the informed consents before enrollment. The Institutional Review
Board of our hospital approved the current study before initiation.

\section{Baseline data collection and assessment}

Patients' clinical characteristics, including demographics (age, gender, education duration, marry status, employment status before surgery, and smoke status), comorbidities (hypertension, hyperlipidemia, diabetes, and chronic kidney disease (CKD)), and disease features (prostate-specific antigen (PSA) level, Gleason score, pathological $\mathrm{T}$ stage, pathological $\mathrm{N}$ stage, surgical margin status), were documented in case report forms on the day of hospital discharge that was defined as baseline (M0). Meanwhile, assessment of anxiety and depression using Zung Self-rating Anxiety/Depression Scale (SAS/SDS) was performed at that time. The assessment was performed by filling the questionnaire by the patients themselves guided by the doctors or nurses, who were blinded to the clinical features of each patient. In detail, before assessment, investigator provided
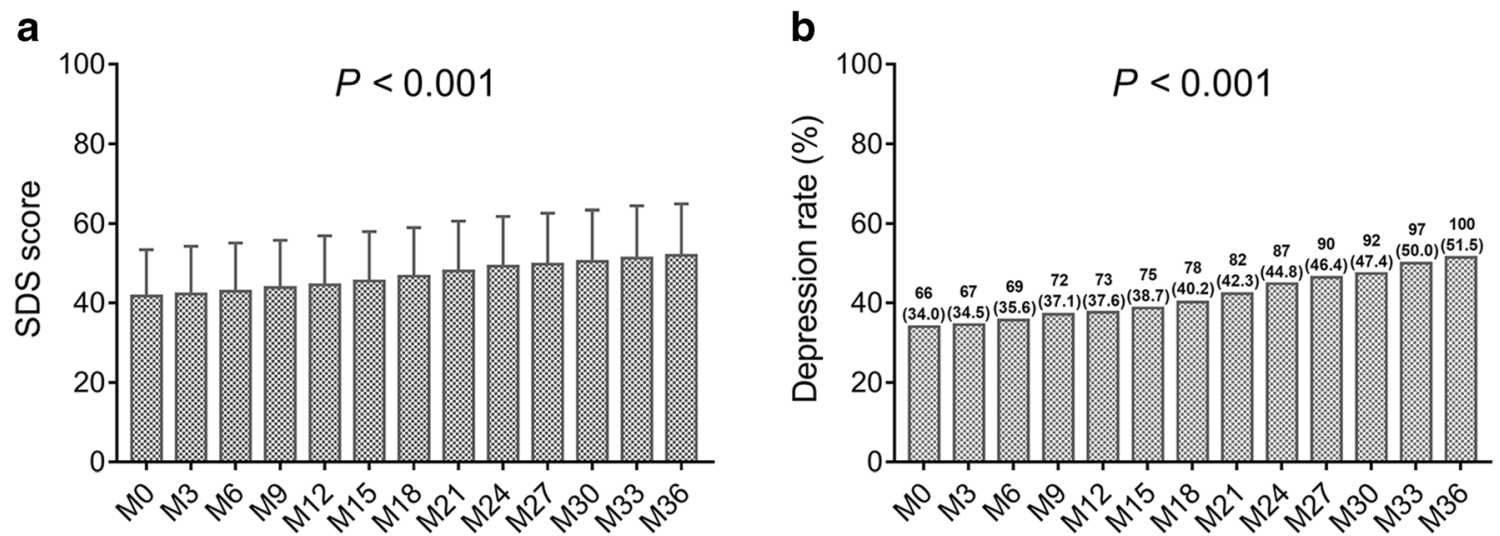

Fig. 2 SDS score and depression rate at each follow-up. The SDS score at each follow-up (a), and depression rate at each follow-up (b) in prostate cancer patients after surgery. SDS, Zung Self-rating Depression scale 
a

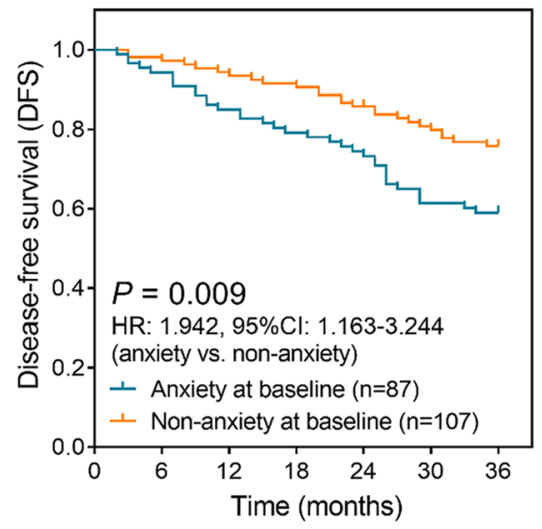

b

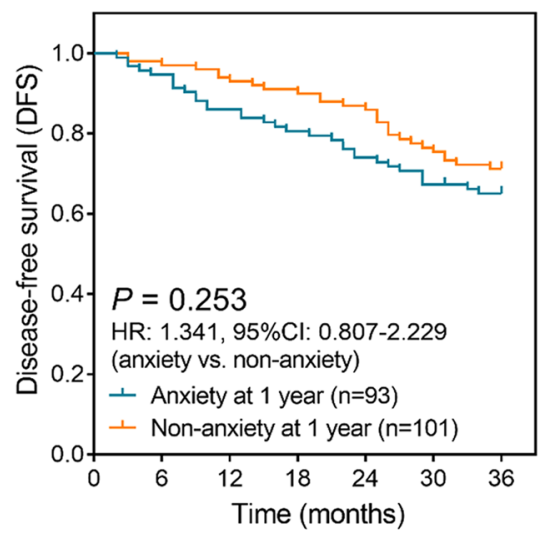

C

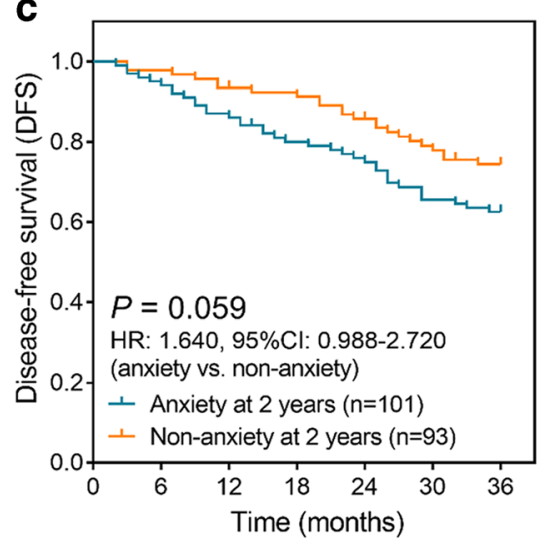

d

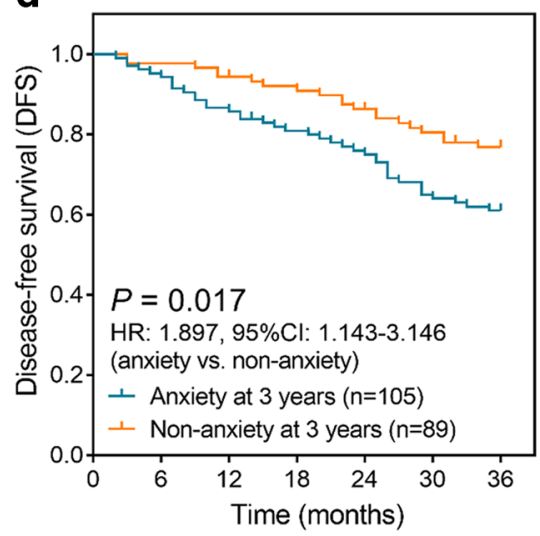

e

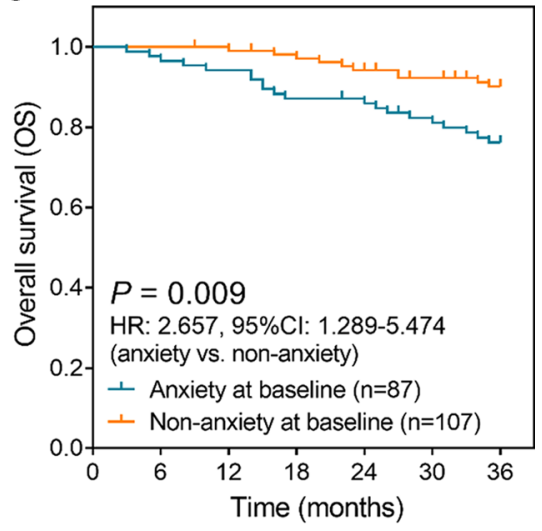

f

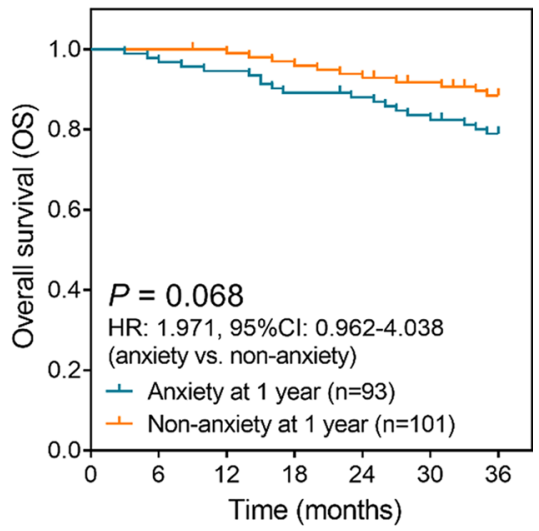

g

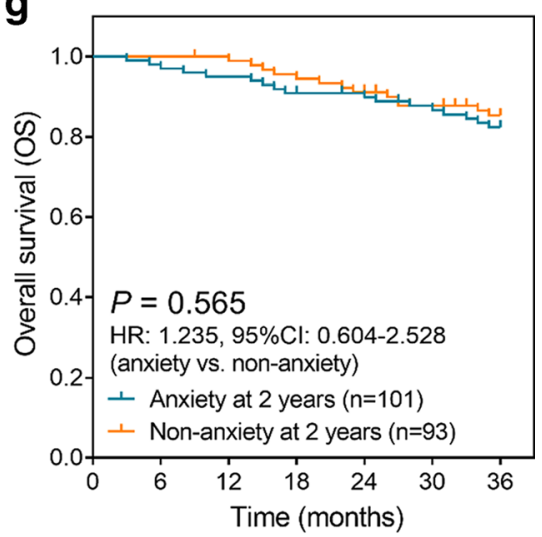

h

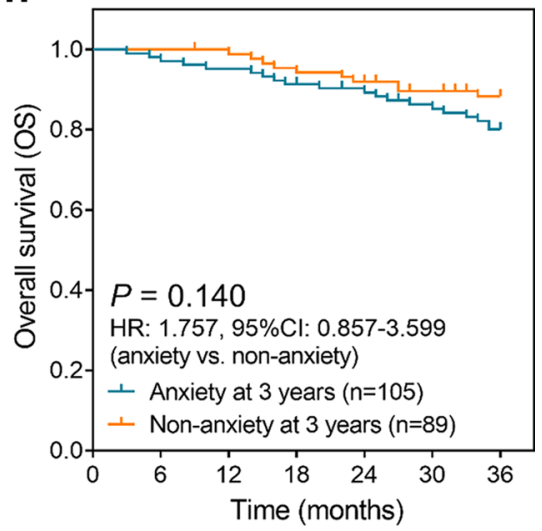


Fig. 3 Anxiety correlated with worse DFS and OS. Difference of DFS in prostate cancer patients with anxiety and patients without anxiety at baseline (a), 1 year (b), 2 years (c), and 3 years (d); difference of OS in prostate cancer patients with anxiety and without anxiety at baseline (e), 1 year (f), 2 years (g), and 3 years (h). DFS, disease-free survival; OS, overall survival; $\mathrm{HR}$, hazard ratio; $95 \% \mathrm{CI}, 95 \%$ confidence interval

instructions about how to fill in the scales, then patients were required to complete the SAS and SDS by themselves.

\section{Follow-up and assessment}

After discharged from hospital, patients were instructed to return to hospital for assessment of anxiety and depression every 3 months (at month 3 (M3), M6, M9, M12, M15, M18, M21, M24, M27, M30, M33, and M36). The trimonthly assessment was continuously performed for a total of 36 months, and the SAS and SDS scores were calculated at each time point. For patients who lost follow-up, the last assessed SAS and SDS scores were used as subsequent missing scores. Besides, in each clinic visit, disease conditions and survival status of patients were documented for evaluation of disease-free survival (DFS) and overall survival (OS).

\section{Anxiety and depression definitions by SAS and SDS}

There were 20 items in SAS and SDS. Each item was scored as $1-4$ points individually, resulting in a $20-80$ raw score. The standard score was calculated by multiplying raw scores by 1.25 ; as a result, the final standard score was ranging from $25 \sim 100$ points. The anxiety was defined as SAS score $\geq 50$; similarly, the depression was defined as SDS score $\geq 50[18,19]$.

\section{Statistical analysis}

Data were presented as mean with standard deviation ( $\mathrm{M} \pm$ $\mathrm{SD})$, median with interquartile range (IQR), or number with percentage (no. (\%)). The data distribution was assessed by the Kolmogorov-Smirnov test. Variation tendency of SAS and SDS score was determined by analysis of variance (ANOVA) followed by the Dunnett test for repeated measurements. Variation tendency of anxiety and depression rate was determined by chi-square test for trend. DFS was calculated from the date of surgery to the date of disease relapse, or patients' death; OS was calculated from the date of surgery to the date of patients' death. Both DFS and OS were displayed by Kaplan-Meier curves, and the comparison of DFS and OS between different subjects was determined by Log-rank test. All potential factors related to DFS or OS were included in conditional multivariate Cox's proportional hazards regression with forward stepwise method to analyze the independent factors. Statistical significance was set at $P$ value $<0.05$. SPSS 22.0 statistical software (IBM, Chicago, IL, USA) and GraphPad Prism 7.02 (GraphPad Software Inc., San Diego, California, USA) were applied for statistical data processing and graphs plotting.

\section{Results}

\section{Characteristics of prostate cancer patients}

Among 194 prostate cancer patients in this study, the mean age was $62.5 \pm 9.0$ years (Table 1). The median of education duration was $9.0(6.0-12.0)$ years, then the numbers of patients with a marry status of married and single/divorced/ widowed were $65(33.5 \%)$ and $129(66.5 \%)$, respectively. In addition, there were 128 (66.0\%) employed patients and 66 (34.0\%) unemployed patients before surgery. The number of smokers was $84(43.3 \%)$. In terms of disease features, the numbers of patients with PSA level $\leq 10 \mathrm{ng} / \mathrm{ml}, 10-20 \mathrm{ng} / \mathrm{ml}$, and $\geq 10-20 \mathrm{ng} / \mathrm{ml}$ were $44(22.7 \%), 107(55.2 \%)$, and 43 $(22.2 \%)$, respectively. There were $44(22.7 \%)$ patients who had Gleason score $\leq 6,107$ (55.2\%) patients who had Gleason score of 7 , and $43(22.2 \%)$ patients who had Gleason score $\geq 8$. And the numbers of patients who had a negative surgical margin and patients who had a positive surgical margin were $160(82.5 \%)$ and 234 (17.5\%), respectively. The other detailed information regarding comorbidities and disease features could be seen in Table 1 .

\section{Anxiety and depression in prostate cancer patients}

At M0, the anxiety rate and depression rate in prostate cancer patients after radical prostatectomy were $44.8 \%$ and $34.0 \%$, respectively. From M0 to M36, in terms of anxiety, the SAS score $(P<0.001)$ (Fig. 1a) and anxiety rate $(P=0.004)$ (Fig. $1 \mathrm{~b})$ were gradually increased in prostate cancer patients. In regard to depression, the SDS score $(P<0.001)$ (Fig. 2a) and depression rate $(P<0.001)$ (Fig. 2 b) were also constantly elevated, and the increase of depression rate numerically exceeded that of anxiety rate. These data indicated that anxiety and depression both became increasingly worse in prostate cancer survivors after radical prostatectomy.

\section{Difference in survival between patients with anxiety and patients without anxiety}

Anxiety at baseline $(P=0.009)$ (Fig. 3a) and anxiety at 3 years $(P=0.017)$ (Fig. $3 \mathrm{~d})$ were correlated with worse DFS in prostate cancer survivors post the surgeries, while anxiety at 1 year $(P=0.253)$ (Fig. 3b) or anxiety at 2 years $(P=0.059)$ (Fig. 3c) was not correlated with DFS. As for OS, anxiety at baseline $(P=0.009)$ (Fig. 3e) associated with shorter OS in prostate 
a
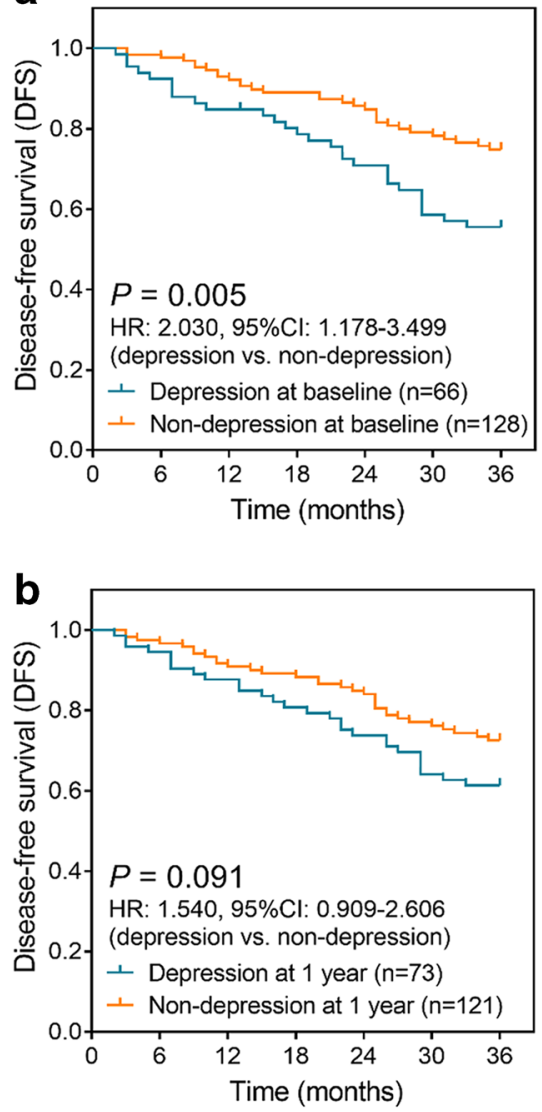

C

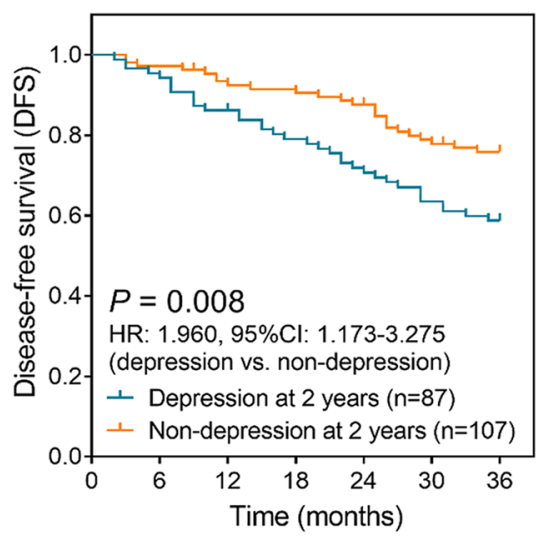

d

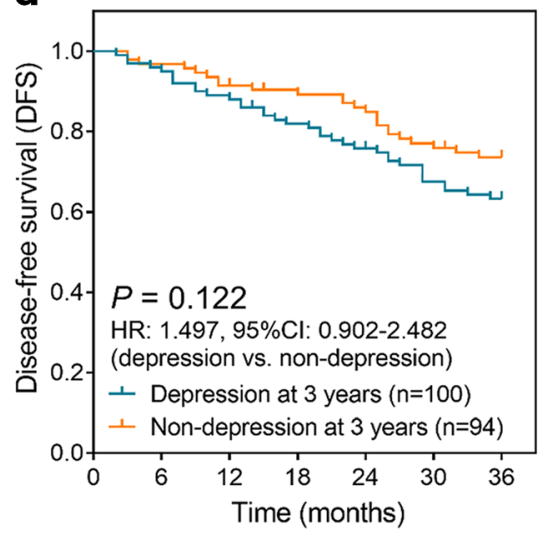

e

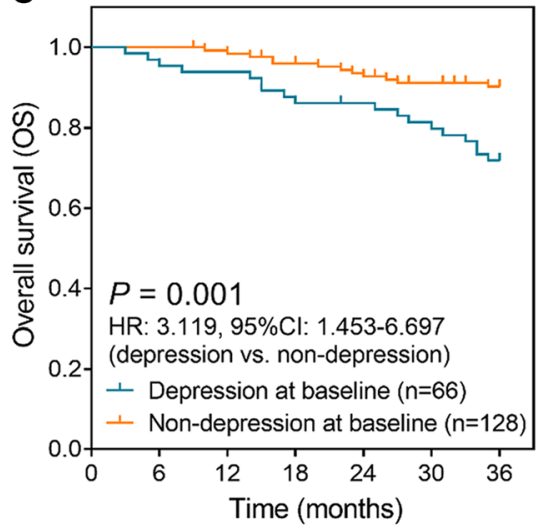

f

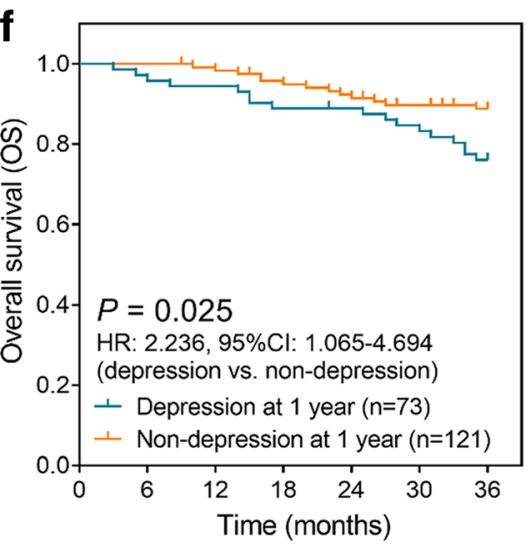

g

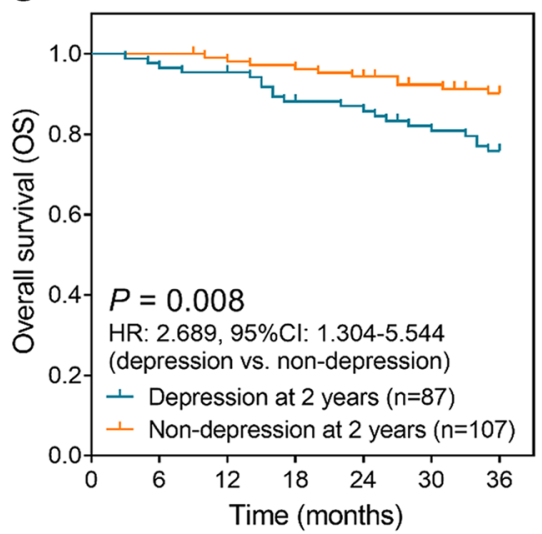

h

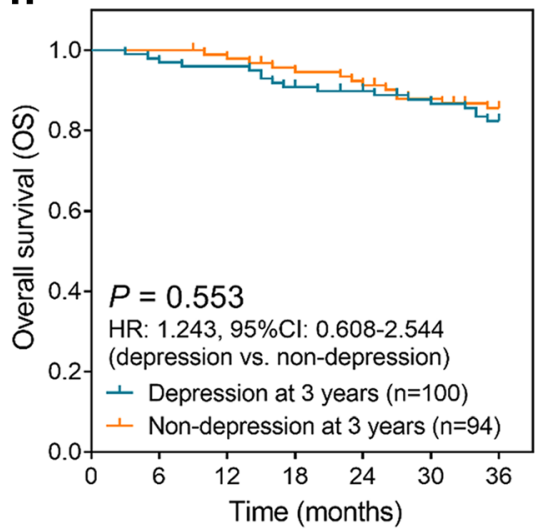


Fig. 4 Depression correlated with worse DFS and OS. Difference of DFS between prostate cancer patients with depression and patients without depression at baseline (a), 1 year (b), 2 years (c), and 3 years (d); difference of OS between prostate cancer patients with depression and patients without depression at baseline (e), 1 year (f), 2 years (g), and 3 years (h). DFS, disease-free survival; OS, overall survival; HR, hazard ratio; $95 \% \mathrm{CI}, 95 \%$ confidence interval

cancer survivors post the surgeries, but anxiety at 1 year $(P=$ $0.068)$ (Fig. 3f), anxiety at 2 years $(P=0.565)$ (Fig. 3g), or anxiety at 3 years $(P=0.140)$ (Fig. 3 h) was not associated with OS. These results suggested that the survival profile was worse in prostate cancer patients with anxiety.

\section{Difference in survivals between patients with depression and patients without depression}

Depression at baseline $(P=0.005)$ (Fig. 4a) and depression at 2 years $(P=0.008)$ (Fig. 4c) were correlated with unfavorable DFS in prostate cancer survivors post the surgeries, while depression at 1 year $(P=0.091)$ (Fig. 4b) or depression at 3 years $(P=0.122)$ (Fig. $4 \mathrm{~d})$ was not associated with DFS. Moreover, depression at baseline $(P=0.001)$ (Fig. 4e), depression at 1 year $(P=0.025)$ (Fig. 4f), and depression at 2 years $(P=0.008)$ (Fig. $4 \mathrm{~g})$ were associated with wore OS, but depression at 3 years $(P=0.553)$ (Fig. 4h) was not correlated with OS. These implied that the survival profile was unfavorable in prostate cancer patients with depression.

\section{Analyses of independent factors related to survival}

Furthermore, multivariate Cox's proportional hazards regression analysis disclosed that depression at baseline $(P=0.027)$ $(\mathrm{HR}=1.796)$ was a factor that could independently predict shorter DFS in prostate cancer patients after radical prostatectomy, besides, the other independent predictive factors for worse DFS were higher Gleason score $(P=0.013)(\mathrm{HR}=$ $1.638)$ and positive surgical margin $(P=0.040)(\mathrm{HR}=$ 1.828) (Table 2). In addition, regarding OS, higher Gleason score $(P=0.014)(\mathrm{HR}=2.007)$, higher pathological $\mathrm{T}$ stage $(P=0.001)(\mathrm{HR}=2.630)$, and positive surgical margin $(P=$ $0.003)(\mathrm{HR}=3.134)$ were independent predictive factors for worse OS (Table 3). These findings suggested that depression at baseline was independently correlated with an elevated risk of relapse in prostate cancer patients.

\section{Discussion}

It is relatively established that anxiety and depression are more likely to occur in cancer patients than in healthy population, with reported prevalence of clinically documented anxiety and depression at approximately $20 \%$ and $10 \%$ according to a previous meta-analysis [5]. While for prostate cancer, neither the epidemiology of anxiety and depression nor the correlation of anxiety and depression with patients' outcome is well investigated. Therefore, we conducted this study, and found in prostate cancer survivors post the surgeries the following: (1) prevalence of anxiety and depression post the surgeries was $44.8 \%$ and $34.0 \%$, respectively; then anxiety and depression both gradually worsened throughout the 3-year follow-up duration. (2) Anxiety and depression both correlated with worse DFS and OS, and baseline depression was an independent predictive factor for unfavorable DFS.

Throughout the long follow-up time of 3 years in the prostate cancer survivors post the surgeries, we found that the prevalence of anxiety and depression was $44.8 \%$ and $34.0 \%$, respectively, and the score and prevalence of anxiety and depression constantly increased from M0 to M36, which obviously caught our attention of the need in psychiatric management. In the previous studies of other cancers, anxiety and depression are also abundantly reported. Such as, a study reports that the prevalence of depressed symptoms assessed by Patient Health Questionnaire-2 (PHQ-2) scale and anxious symptoms assessed by Generalized Anxiety Disorder-2 (GAD-2) scale in breast cancer patients are $38.2 \%$ and $32.2 \%$, respectively [20]. And a register-based study that enrolls 3370 working age cancer survivors (who are diagnosed with cancer $25-55$ years before) illuminates that $40 \%$ of the participants present with moderate to high anxiety score (assessed by German version of HADS scale) [21]. Additionally, a study with a large sample size of 29,366 women diagnosed with breast or other genital organ cancer demonstrates that there are 7994 patients with confirmed depression or anxiety, the incidence of anxiety or depression in
Table 2 Multivariate Cox's proportional hazards regression analysis of factors related to DFS

\begin{tabular}{lllllll}
\hline Factors & \multicolumn{6}{c}{ Multivariate Cox's proportional hazards regression analysis } \\
\cline { 2 - 7 } & $\mathrm{B}$ & $\mathrm{SE}$ & Wald & $P$ value & HR & 95\% CI (lower-upper) \\
\hline Depression at baseline & 0.586 & 0.265 & 4.890 & 0.027 & 1.796 & $1.069-3.018$ \\
Higher Gleason score & 0.493 & 0.198 & 6.181 & 0.013 & 1.638 & $1.110-2.417$ \\
Positive surgical margin & 0.603 & 0.294 & 4.221 & 0.040 & 1.828 & $1.028-3.251$ \\
\hline
\end{tabular}

$D F S$, disease-free survival; $S E$, standard error; $H R$, hazards ratio; $C I$, confidence interval 
Table 3 Multivariate Cox's proportional hazards regression analysis of factors related to OS

\begin{tabular}{lllrllll}
\hline \multirow{2}{*}{ Factors } & \multicolumn{6}{c}{ Multivariate Cox’s proportional hazards regression analysis } \\
\cline { 2 - 7 } & B & \multicolumn{1}{l}{ SE } & Wald & P value & HR & 95\% CI (lower-upper) \\
\hline Higher Gleason score & 0.696 & 0.284 & 6.019 & 0.014 & 2.007 & $1.150-3.500$ \\
Higher pathological T stage & 0.967 & 0.303 & 10.207 & 0.001 & 2.630 & $1.453-4.760$ \\
Positive surgical margin & 1.142 & 0.379 & 9.063 & 0.003 & 3.134 & $1.490-6.592$ \\
\hline
\end{tabular}

$O S$, overall survival; $S E$, standard error; $H R$, hazards ratio; $C I$, confidence interval breast cancer patients is 8.8 every 100 person-years, and in patients with other genital organ cancer is 5.9 per 100 personyears [22]. As for the findings in our study, they could be explained by the following aspects. First, stress is the predominant cause of anxiety and depression, and coping with prostate cancer, its clinical symptoms, and treatment certainly result in increased stress in prostate cancer patients, which increases the risk of developing mood disorders including anxiety and depression. Second, studies report that the change of testosterone level and androgen deprivation therapy may also play a role in the development of anxiety and depression in prostate cancer patients [23]. Third, radical prostatectomy normally results in a reduced quality of prostate cancer patients' domestic life, and may also damage patients' self-esteem; these all constantly contribute to the developments of anxiety and depression. Additionally, we would like to note that other scales may be needed to assess the anxiety and depression in our patients; however, it was difficult to apply another scale since the data in our study was retrospectively analyzed.

In this study, we also discovered that post-surgery anxiety and depression are associated with worse survival profile, and post-surgery depression could independently predict worse DFS in prostate cancer patients. Previous studies all indicate that anxiety and depression are not uncommon in cancer patients; for this reason, many clinicians are trying to reveal some veiled mechanisms. A study elucidates that depression plays a role in enhancing the progression of hepatocellular carcinoma in mice via increasing programmed death 1 (PD1) level regulated by glucocorticoids in tumor infiltrating natural killer (NK) cells [24]. Another study reveals that depression correlates with worse clinical outcome in gastric cancer patients, and the in vivo and in vitro experiments disclose that gastric cancer-related depression involves the participation of reactive oxygen species via the ABL1-modulated inflammatory pathway [25]. In addition, a previous study illustrates that anxiety and depression play a role in mediating the correlation of chemotherapy-induced peripheral neuropathy with fatigue in colorectal cancer patients; however, this study also states that this needs more experimental evidence to validate [26]. Furthermore, there are already findings regarding cellular mechanisms of the harmful impact of anxiety and depression on prostate cancer patients. For instance, in mouse model of prostate cancer, depression is illuminated to increase the infiltration of myeloid cells and interleukin-6 (IL-6) expressions via mediating sympathetic neuropeptide Y (NPY) signaling pathway and subsequently enhances the tumor growth [27].

And in the clinical setting, there are also studies about the pejorative role of anxiety and depression in cancer patients' prognosis. For example, a previous study reveals that in oropharynx cancer patients, the self-report depression independently correlates with unfavorable OS and DFS, which is partially similar to our results [28]. In accordance with this, another study reports that in postoperative non-small cell lung cancer patients, post-surgery anxiety predicts shorter OS, and post-surgery anxiety and depression both predict less prolonged DFS [29]. In terms of our results, we tried to explain them by the following possible reasons. First, prostate cancer patients are more likely to have a low adherence to therapies, and this could contribute to a worse treatment efficacy and thus a worse prognosis [30]. Second, anxiety and depression also induce many physical symptoms, such as fatigue, insomnia, and change of weight as well as appetite; these all contribute to a worse physical function and may interfere with the physical health of prostate cancer patients $[31,32]$. Third, anxiety and depression may aggregate the disease in prostate cancer patients via affecting several biological processes or pathways, such as regulating the tumor infiltrating NK cells and reactive oxygen species [24-27]. In the future, the status of anxiety and depression may be useful in optimizing the prognosis prediction in surgical prostate cancer patients; however, this should be validated by more highquality trials or large-scale cohort studies.

Furthermore, there were a few limitations we liked to discuss. First, we only included surgical prostate cancer patients, which indicated that our findings were not applicable in patients who were not suitable for surgery. Second, we would like to enroll more patients in the future study due to that the sample size in this study was comparatively small, and this may result in an insufficient statistical power.

Altogether, anxiety and depression both gradually deteriorate, and they correlate with unfavorable survival profile in prostate cancer patients after radical prostatectomy.

Funding This study was supported by Nature Science Foundation of Hubei Province (No. 2017CFC851). 
Compliance with ethical standards All patients signed the informed consents before enrollment. The Institutional Review Board of our hospital approved the current study before initiation.

Competing interests The authors declare that they have no conflict of interest.

Open Access This article is licensed under a Creative Commons Attribution 4.0 International License, which permits use, sharing, adaptation, distribution and reproduction in any medium or format, as long as you give appropriate credit to the original author(s) and the source, provide a link to the Creative Commons licence, and indicate if changes were made. The images or other third party material in this article are included in the article's Creative Commons licence, unless indicated otherwise in a credit line to the material. If material is not included in the article's Creative Commons licence and your intended use is not permitted by statutory regulation or exceeds the permitted use, you will need to obtain permission directly from the copyright holder. To view a copy of this licence, visit http://creativecommons.org/licenses/by/4.0/.

\section{References}

1. Kessler RC, Bromet EJ (2013) The epidemiology of depression across cultures. Annu Rev Public Health 34:119-138. https://doi. org/10.1146/annurev-publhealth-031912-114409

2. Baxter AJ, Scott KM, Vos T, Whiteford HA (2013) Global prevalence of anxiety disorders: a systematic review and meta-regression. Psychol Med 43(5):897-910. https://doi.org/10.1017/ S003329171200147X

3. Mal K, Awan ID, Ram J, Shaukat F (2019) Depression and anxiety as a risk factor for myocardial infarction. Cureus 11(11):e6064. https://doi.org/10.7759/cureus.6064

4. Polikandrioti M, Tzirogiannis K, Zyga S, Koutelekos I, Vasilopoulos G, Theofilou P, Panoutsopoulos G (2018) Effect of anxiety and depression on the fatigue of patients with a permanent pacemaker. Arch Med Sci Atheroscler Dis 3:e8-e17. https://doi. org/10.5114/amsad.2018.73231

5. Mitchell AJ, Chan M, Bhatti H, Halton M, Grassi L, Johansen C, Meader N (2011) Prevalence of depression, anxiety, and adjustment disorder in oncological, haematological, and palliative-care settings: a meta-analysis of 94 interview-based studies. Lancet Oncol 12(2):160-174. https://doi.org/10.1016/S1470-2045(11)70002-X

6. Steel Z, Marnane C, Iranpour C, Chey T, Jackson JW, Patel V, Silove D (2014) The global prevalence of common mental disorders: a systematic review and meta-analysis 1980-2013. Int J Epidemiol 43(2):476-493. https://doi.org/10.1093/ije/dyu038

7. Breitbart W, Rosenfeld B, Tobias K, Pessin H, Ku GY, Yuan J, Wolchok J (2014) Depression, cytokines, and pancreatic cancer. Psychooncology 23(3):339-345. https://doi.org/10.1002/pon.3422

8. Jick S, Li L, Gastanaga VM, Liede A (2015) Prevalence of hypercalcemia of malignancy among cancer patients in the UK: analysis of the Clinical Practice Research Datalink database. Cancer Epidemiol 39(6):901-907. https://doi.org/10.1016/j.canep.2015.10.012

9. Wick W, Hertenstein A, Platten M (2016) Neurological sequelae of cancer immunotherapies and targeted therapies. Lancet Oncol 17(12):e529-e541. https://doi.org/10.1016/S1470-2045(16)30571-X

10. Bortolato B, Hyphantis TN, Valpione S, Perini G, Maes M, Morris G, Kubera M, Köhler CA, Fernandes BS, Stubbs B, Pavlidis N, Carvalho AF (2017) Depression in cancer: the many biobehavioral pathways driving tumor progression. Cancer Treat Rev 52:58-70. https://doi.org/10.1016/j.ctrv.2016.11.004
11. Haskins CB, McDowell BD, Carnahan RM et al (2019) Impact of preexisting mental illness on breast cancer endocrine therapy adherence. Breast Cancer Res Treat 174(1):197-208. https://doi.org/ 10.1007/s10549-018-5050-1

12. Bray F, Ferlay J, Soerjomataram I, Siegel RL, Torre LA, Jemal A (2018) Global cancer statistics 2018: GLOBOCAN estimates of incidence and mortality worldwide for 36 cancers in 185 countries. CA Cancer J Clin 68(6):394-424. https://doi.org/10.3322/caac. 21492

13. Nguyen-Nielsen M, Borre M (2016) Diagnostic and therapeutic strategies for prostate Cancer. Semin Nucl Med 46(6):484-490. https://doi.org/10.1053/j.semnuclmed.2016.07.002

14. Komura K, Sweeney CJ, Inamoto T, Ibuki N, Azuma H, Kantoff PW (2018) Current treatment strategies for advanced prostate cancer. Int J Urol 25(3):220-231. https://doi.org/10.1111/iju.13512

15. Howlader N NA, Krapcho M, Miller D, Bishop K, Kosary CL, Yu M, Ruhl J, Tatalovich Z, Mariotto A, Lewis DR, Chen HS, Feuer EJ, Cronin KA, SEER cancer statistics review, National Cancer Institute, SEER web site, 2017

16. Noonan EM, Farrell TW (2016) Primary care of the prostate cancer survivor. Am Fam Physician 93(9):764-770

17. Nead KT, Sinha S, Yang DD et al (2017) Association of androgen deprivation therapy and depression in the treatment of prostate cancer: a systematic review and meta-analysis. Urol Oncol 35(11):664 e661-664 e669. https://doi.org/10.1016/j.urolonc.2017.07.016

18. Gainotti G, Cianchetti C, Taramelli M, Tiacci C (1972) The guided self-rating anxiety-depression scale for use in clinical psychopharmacology. Act Nerv Super (Praha) 14(1):49-51

19. Zung WW, Gianturco JA (1971) Personality dimension and the Self-Rating Depression Scale. J Clin Psychol 27(2):247-248. https://doi.org/10.1002/1097-4679(197104)27:2<247::aidjclp2270270230>3.0.co;2-6

20. Tsaras K, Papathanasiou IV, Mitsi D et al (2018) Assessment of depression and anxiety in breast cancer patients: prevalence and associated factors. Asian Pac J Cancer Prev 19(6):1661-1669. https://doi.org/10.22034/APJCP.2018.19.6.1661

21. Inhestern L, Beierlein V, Bultmann JC, Möller B, Romer G, Koch U, Bergelt C (2017) Anxiety and depression in working-age cancer survivors: a register-based study. BMC Cancer 17(1):347. https:// doi.org/10.1186/s12885-017-3347-9

22. Jacob L, Kalder M, Kostev K (2017) Incidence of depression and anxiety among women newly diagnosed with breast or genital organ cancer in Germany. Psychooncology 26(10):1535-1540. https://doi.org/10.1002/pon.4328

23. Dinh KT, Reznor G, Muralidhar V, Mahal BA, Nezolosky MD, Choueiri TK, Hoffman KE, Hu JC, Sweeney CJ, Trinh QD, Nguyen PL (2016) Association of androgen deprivation therapy with depression in localized prostate cancer. J Clin Oncol 34(16): 1905-1912. https://doi.org/10.1200/JCO.2015.64.1969

24. Zhao Y, Jia Y, Shi T, Wang W, Shao D, Zheng X, Sun M, He K, Chen L (2019) Depression promotes hepatocellular carcinoma progression through a glucocorticoids mediated up-regulation of PD-1 expression in tumor infiltrating NK cells. Carcinogenesis. https:// doi.org/10.1093/carcin/bgz017

25. Huang T, Zhou F, Yuan X, Yang T, Liang X, Wang Y, Tu H, Chang J, Nan K, Wei Y (2019) Reactive oxygen species are involved in the development of gastric cancer and gastric cancerrelated depression through ABL1-mediated inflammation signaling pathway. Oxidative Med Cell Longev 2019:5813985-5813912. https://doi.org/10.1155/2019/5813985

26. Bonhof CS, van de Poll-Franse LV, Vissers PAJ et al (2019) Anxiety and depression mediate the association between chemotherapy-induced peripheral neuropathy and fatigue: results from the population-based PROFILES registry. Psychooncology 28(9):1926-1933. https://doi.org/10.1002/pon.5176 
27. Cheng Y, Tang XY, Li YX, Zhao DD, Cao QH, Wu HX, Yang HB, Hao K, Yang Y (2019) Depression-induced neuropeptide Y secretion promotes prostate cancer growth by recruiting myeloid cells. Clin Cancer Res 25(8):2621-2632. https://doi.org/10.1158/10780432.CCR-18-2912

28. Shinn EH, Valentine A, Jethanandani A, Basen-Engquist K, Fellman B, Urbauer D, Atkinson E, Yusuf SW, Lenihan D, Woods ML, Kies MS, Sood AK, Carmack C, Morrison WH, Gillenwater A, Sturgis EM, Garden AS (2016) Depression and oropharynx cancer outcome. Psychosom Med 78(1):38-48. https://doi.org/10.1097/PSY.0000000000000256

29. Huang X, Zhang TZ, Li GH, Liu L, Xu GQ (2020) Prevalence and correlation of anxiety and depression on the prognosis of postoperative non-small-cell lung cancer patients in North China. Medicine
(Baltimore) 99(11):e19087. https://doi.org/10.1097/MD. 0000000000019087

30. DiMatteo MR, Hanskard-Zolnierek KB (2011) Impact of depression on treatment adherence and survival from cancer. In: Kissane DW, Maj M, Sartorius N (eds) Depression and cancer, 1st edn. Wiley-Blackwell, p 101-24

31. Malhi GS, Mann JJ (2018) Depression. Lancet 392(10161):2299 2312. https://doi.org/10.1016/S0140-6736(18)31948-2

32. Craske MG, Stein MB (2016) Anxiety. Lancet 388(10063):30483059. https://doi.org/10.1016/S0140-6736(16)30381-6

Publisher's note Springer Nature remains neutral with regard to jurisdictional claims in published maps and institutional affiliations. 